\title{
Crecimiento y actividad de las bacterias fotosintéticas del azufre en relación con gradientes físico-químicos en ecosistemas acuáticos
}

\author{
Emilio Montesinos
}

Departamento de Microbiología. Facultad de Ciencias e Instituto de Biología Fundamental Universidad Autónoma de Barcelona, Bellaterra (Barcelona) España.

\section{SUMMARY \\ GROWTH AND ACTIVITY OF PHOTOTROPHIC SULFUR BACTIER IA ACROSS PIFYSICO-CHIMICAL GRADIIENTS IN NATURI:.}

Growth of phototrophic bacteria in the presence of physico-chemical gradients in lakes is characterized by the formation of plates up to $10^{7}$ cells $/ \mathrm{ml}$. Physiological activity of Chromatium minus and Chlorobium phacovibrioides across fine vertical profiles in Cisó (Girona, NE: Spain) and Cullera (Valencia, E Spain) lakes was studied by means of photoassimilation of ${ }^{14} \mathrm{CO}_{2}$, specific pigment content, ultrathin sections and size frequency distribution of the cells.

Bacterial populations grow actively only in the upper part of the plate. In depths with the maximum bacterial concentration, very low levels of photosythesis and growth take place, due to the strong self-shading effect. A model on the development of plates is discussed in relation to water density and light gradients.

\section{INTRODUCCION}

El crecimiento de las bacterias fotosintéticas en los ambientes acuáticos está primariamente determinado por la energía luminosa disponible y su naturaleza espectral, asi como por la concentración de sulfhidrico que es utilizado como donador de electrones en la fotosíntesis (TRUPER \& GENOVESE, 1968; PARKIN \& BROCK, 1980). Típicamente forman láminas de $10^{6}$ a $10^{8} \mathrm{cel} / \mathrm{ml}$ a profundidades donde desaparece la luz y existe sulfhidrico, generalmente por debajo del punto de compensación entre produc- ción y respiración de las algas (TAKAHASHI \& ICHIMURA, 1968).

$\mathrm{El}$ interés de este trabajo se ha centrado en la ecofisiologia de las bacterias fotosintéticas del azufre y su crecimiento en ecosistemas acuáticos anaeróbicos y el propósito más concreto ha sido analizar el crecimiento y actividad de dichas poblaciones cuando se desarrollan en presencia de fuertes gradientes de luz y sulfhidrico. Se han aplicado técnicas que permiten determinar el estado fisiológico de las células, principalmente mediante la fotoincorporación de radioisótopos y el análisis de la distri- 
bución de frecuencias de los tamaños celulares con el contador de Coulter.

\section{MATERIAL Y METODOS}

\section{ZONA DE ESTUDIO}

Se han estudiado dos lagos que poseen densas poblaciones de bacterias fotosintéticas del azufre durante todo su ciclo anual. La laguna de Cisó es holomíctica anaeróbica y está situada en la zona cárstica de Banyoles (Girona) (GUERRERO \& ABELLA, 1978). El lago de Cullera es un estuario que posee agua marina anaeróbica en el fondo (Cullera, Valencia) y ha sido utilizado a efectos comparativos en este trabajo (Datos sin publicar).

\section{TECNIC AS DE MUESTREO}

Las muestras se tomaban durante el mediodía solar siguiendo un perfil vertical sobre el punto de máxima profundidad de cada estación.

Las profundidades de muestreo se establecran después de determinar la situación precisa de las bacterias fotosintéticas con un turbidimetro y las muestras se obtenian con una bomba peristáltica manual (WAB modelo LPA-2) para minimizar la exposición a la luz $\dot{y}$ al oxígeno, y con el fin de realizar una. toma precisa.

\section{ANALISIS FISICO-QUIMICOS}

La energía luminosa se determinaba a cada profundidad con un radiómetro Crump modelo 550 que utilizaba un fotodiodo sumergible sensor de cuantos. La conductividad y la temperatura se analizaban con un aparato YSI modelo 33 (Yellow Spring Instruments). Los análisis químicos de sulfhidrico, alcalinidad y sulfatos se realizaban según GOLTERMAN et al. (1973).
RECUENTO MICROSCOPICO DIRECTO DEL NUMERO DE BACTERIAS

El recuento directo de bacterias se ha realizado sobre filtros Nuclepore de $0,2 \mu \mathrm{m}$ de poro según la técnica de HOBBIE et al. (1977) utilizando como fluorocromo el anaranjado de acridina. Las bacterias se contaban con un microscopio Olympus $\mathrm{BH}$ a $1.250 \mathrm{X}$. Se realizaba un análisis estadístico de 30 campos por filtro escogidos al azar.

\section{RECUENTO ELECTRONICO DE PARTICULAS}

Se utilizó un contador de Coulter modelo ZB equipado con tubos de 19 y $30 \mu \mathrm{m}$ de apertura que permiten cuantificar particulas de un volumen esférico equivalente entre 0,05 y $50 \mu^{3}$. El electrolito utilizado era Isoton, y el aparato se calibraba con esferas de latex de 4,18 y $15,10 \mu \mathrm{m}^{3}$. Los resultados se corregian teniendo en cuenta la coincidencia.

\section{ACTIVIDAD FOTOSINTETICA}

Se determinaba mediante la incorporación de radiuisótopo ${ }^{14} \mathrm{CO}_{2}$. A cada botella de $25 \mathrm{ml}$ de muestra se le añadían $10 \mathrm{mi}$ crocuries de $\mathrm{NaH}-{ }^{14} \mathrm{CO}_{2}$ incubando cada pareja de botellas (una transparente y otra oscura) a la profundidad original de la que procedia la muestra. Después de 30 minutos de incubación, ésta se interrumpia al introducir las botellas en hielo y en la oscuridad e inmediatamente se procedia a filtrar $15 \mathrm{ml}$ a través de filtros de membrana Sartorius de 0,45 micras de poro. Para la eliminacion del isótopo no asimilado se depositaba el filtro en un vial de centelleo con $0,2 \mathrm{ml}$ de $\mathrm{HCl}$ 2N. Posteriormente so añadian $8 \mathrm{ml}$ de $\mathrm{l} i$ quido de centelleo Handifluor (Mallinckrodt Inc.), se media la radioactividad con un contador Nuclear Chicago modelo Unilux II y los resultados se corregían para el amortiguamiento mediante estandarización intema. La producción se calculaba teniendo en cuenta la alcalinidad total, conductividad y 


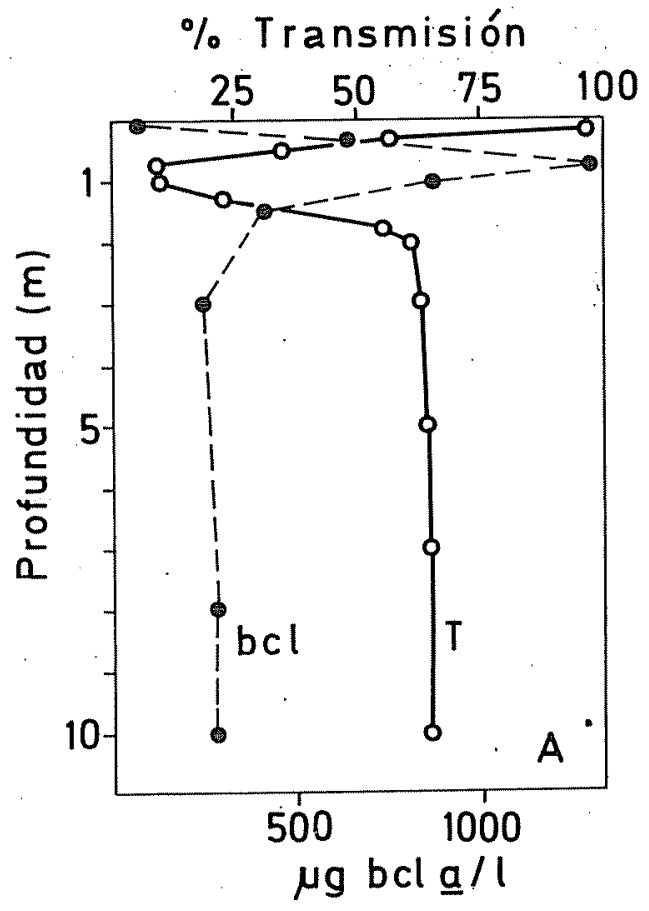

$\%$ Transmisión

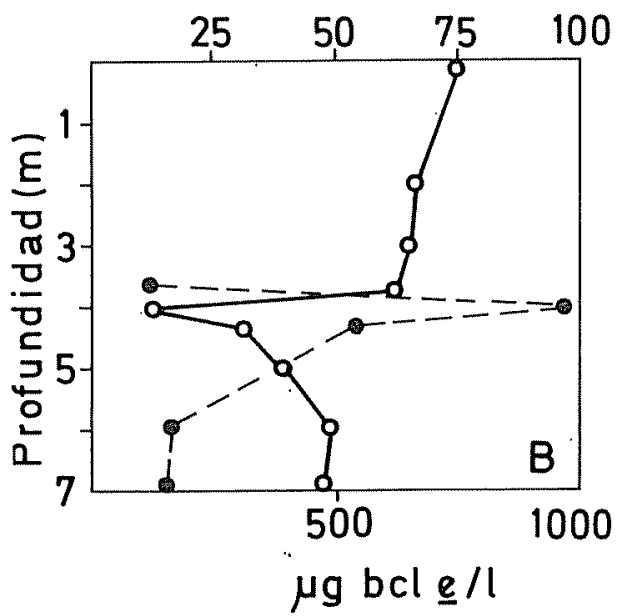

ligura 1. Distribución vertical de la turbidez (porcentaje de transmisión respecto al aire) y de la concentración de bacterioclorofilas en Cisó durante d día 28.8.81 (A) y en Cullera el día 31.6.81 (B).
pH (VOLLENWEIDER, 1974). La actividad fotosintética especifica se obtenía refiriendo los valores de producción a la concentración de proteínas determinada por el método del azul de Coomassie (BRADFORD, 1976).

\section{RESULTADOS \\ DISTRIBUCION VERTICAL DE LAS POBLACIONES}

Las bacterias fotosintéticas del azufre desarrollan densas poblaciones en lagos holomícticos anaeróbicos (Cisó) y en lagos meromícticos o estuarios que presentan sulfhídrico en las capas profundas (Cullera). En condiciones óptimas forman láminas con concentraciones de células que llegan hasta $10^{8} \mathrm{cel} / \mathrm{ml}$ dando lugar a capas de agua turbia coloreada de intensos tonos rosados, marrones o verdes dependiendo de la composición de especies.

La situación y forma precisa de dichas capas en el perfil vertical de los diferentes lagos se ha estudiado mediante perfiles turbidimétricos. En este trabajo se ha utilizado un turbidimetro vertical sumergible de diseño y construcción propia (MONTESINOS, 1982). En la figura 1 se representan los perfiles turbidimétricos (expresados en porcentaje de transmisión respecto al aire) en la laguna de Cisó (28.8.81) y en Cullera (31.6.81) durante la formación de láminas bacterianas. Las distribuciones verticales muestran una típica asimetria, presentando una pendiente brusca en la parte superior y una disminución exponencial suave en profundidad.

En general existen dos tipos de distribución vertical de las poblaciones bacterianas dependiendo de la presencia de gradientes fisicoquímicos verticales. En la laguna de Cisó, cuando no existen gradientes, durante la holomixis, las células se distribuyen uniformemente por toda la columna de agua debido a la mezcla térmica y a la uniformidad de los parámetros fisicoquímicos como consecuencia de la entrada de agua freática por el fondo. Dicha distribución puede apreciarse en Cisó durante el invierno 


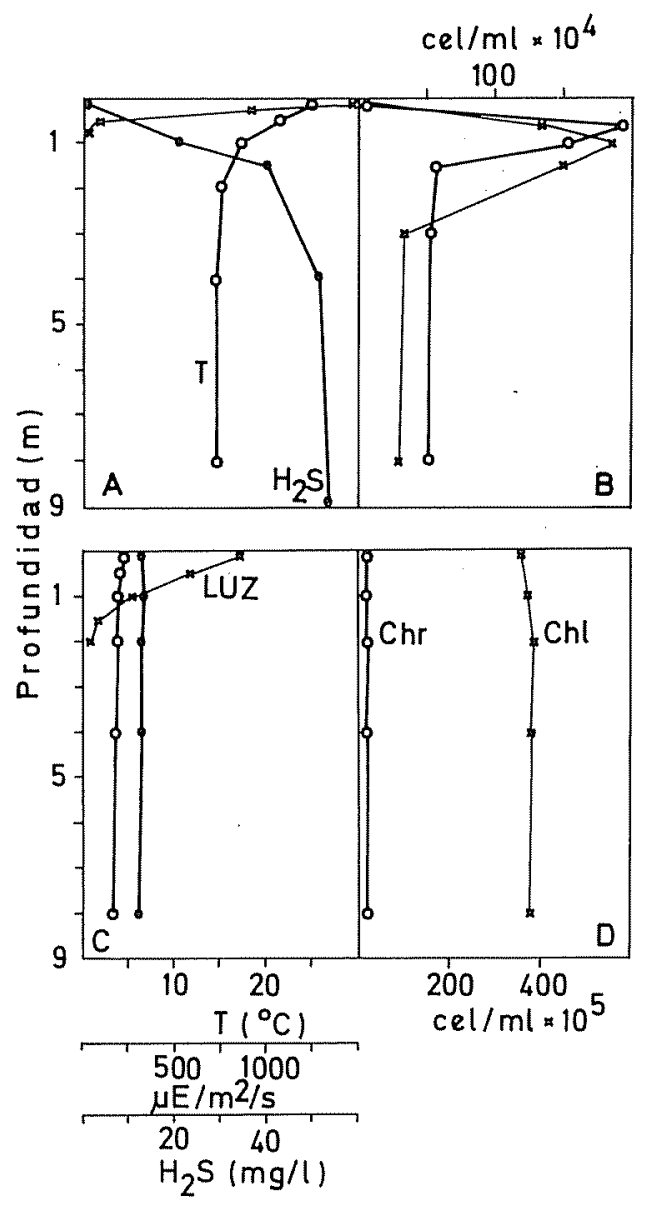

Figura 2. Distribución vertical de los parámetros fisicoquímicos: temperatura, concentración de sulfhídrico, energáa luminosa $(A, C)$ y número total de Chromatium y Chlorobium (B, D) durante un dia de verano (28.8.81) (narte superior) e inviemo (16.2.81) (parte inferior).

(véase la figura 2) en que la temperatura, $\mathrm{H}_{2} \mathrm{~S}$ y conductividad son columnares. $\mathrm{Si}$ existen gradientes fisicoquínicos, bien porque se trate de lagos meromícticos 0 estuarios, o bien en lagos holomicticos anacróbicos como Cisó durante la estratificación térmica estival (véase la figura 2) las poblaciones se distribuyen formando láminas que reflejan el delicado balance de condiciones requerido para su creci-
TABLA I. Distribución vertical de la energía luminosa, biomasa y actividad fotosintética específica de las poblaciones bacterianas fotosintéticas de la laguna de Cisó (28.8.81).

\begin{tabular}{|c|c|c|c|}
\hline 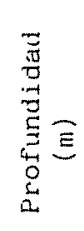 & 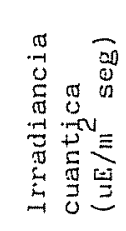 & 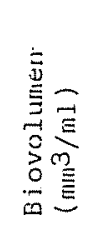 & 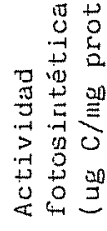 \\
\hline 0,25 & 850 & 2,75 & 159.1 \\
\hline 0,60 & 25 & 7,81 & 94,7 \\
\hline 0,75 & $i$ & 12,50 & 44,7 \\
\hline 1,00 & 0,25 & 6,32 & 2,4 \\
\hline 3,00 & 0,01 & 3,75 & 5,2 \\
\hline 8,00 & - & 3,22 & 10,1 \\
\hline
\end{tabular}

miento óptimo: suficiente luz, $\mathrm{H}_{2} \mathrm{~S}$ y un fuerte gradiente térmico o químico.

Durante la formación de estas láminas y como resultado de la elevada densidad poblacional existe un fuerte gradiente de luz cercano a la superficie (coeficiente de extinción global de la luz, $\mathrm{n}=7,2 \mathrm{~m}^{-1}$ ). En el punto de máxima concentración bacteriana donde se acumula Chromatium minus $(0,75 \mathrm{~m}$.) la irradiancia cuántica es menor de 1 microeinstein $/ \mathrm{m}^{2}$ seg. (mientras que en la superficie es de 1.000 a $1.500 \mu \mathrm{E} / \mathrm{m}^{2}$ seg.), condiciones en las que no ex iste crecimiento fototrófico en cultivos puros de laboratorio de $C$. minus o de Chlorobium sp. (Datos no publicados).

\section{DISTRIBUCION VERTICAL DE LA ACTIVIDAD FOTOSINTETICA}

En la tabla I se exponen los resultados de las distribuciones verticales de energía luminosa y de la biomasa (fotosintética (en $\mathrm{mm}^{3} / \mathrm{ml}$ ) respecto de la actividad de fotoasimilación de $\mathrm{CO}_{2}$. Se puede apreciar una discordancia entre la profundidad de acumulación de la biomasa $(0,75 \mathrm{~m}$.) y los niveles 
TABL A II Características de las distribuciones de tamaño de la población de Chromatium minus a lo largo del perfil vertical en la laguna de Cisó.
TABLA III. Características de las distribuciones de tamaños de la población de Chlorobium placovibrioides a lo largo del perfil vertical, en la laguna de Cullera.

\begin{tabular}{|c|c|c|c|c|}
\hline 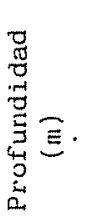 & 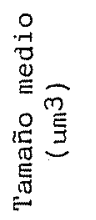 & 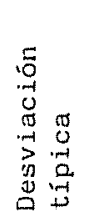 & 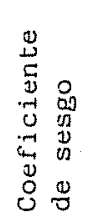 & $\begin{array}{l}n \\
n \\
0 \\
0 \\
\vdots \\
\vdots \\
3\end{array}$ \\
\hline 75 & 0,225 & 0,094 & 0,625 & 2,272 \\
\hline & 0,179 & 0,084 & 0,970 & 4,014 \\
\hline 00 & 0,158 & 0,071 & 1,164 & 4,612 \\
\hline & 0,113 & 0,047 & 1,426 & 6,210 \\
\hline
\end{tabular}

donde se detecta la máxima fotoasimilación $(0,25 \mathrm{~m}$.). La actividad fotosintética está bien correlacionada con la disponibilidad de energia de manera que los valores máximos se obtienen por encina de la lámina de bar:terias (donde son 4 veces superiores a las del punto de máxima biomasa) como consecuencia del fuerte efecto de autosombreado de las células.

\section{DISTRIBUCION VERTICAL DE LAS DISTRIBUCIONES DE TAMAÑOS DE LAS CELULAS}

Simultáneamente con los experimentos de fotoincorporación de ${ }^{14} \mathrm{CO}_{2}$ se ha aplicado la técnica de análisis de la distribución de frecuencias de los tamaños celulares con el contador de Coulter (ZARITSKY \& PRITCHARD, 1973). La técnica se basa en que existe una relación directa entre la velocidad de crecimiento de un microorganismo y su tamaño medio. En la población de $C$. minus en Cisó se aprecian distribuciones de tamaños que indican un decrecimiento progresivo del tamaño medio de las células por debajo de la capa de máxima concentración de células $\left(x=14,67 \mu \mathrm{m}^{3}\right.$ a $0,6 \mathrm{~m}$. y de $12,79 \mu \mathrm{m}^{3}$ a $3 \mathrm{~m}$.) y un aumento de la curtosis de dichas distribuciones con la profundidad (curtosis, $\mathrm{c}=3,18$ a $0,6 \mathrm{~m}$. y 3,65 a $3 \mathrm{~m}$.) (véase la tabla II). En Cullera la po- blación de Chlorobium phaeovibrioides muestra diferencias mucho más claras a medida que aumenta la profundidad (véase la tabla III). Por encima de la capa de máxima concentración de celulas, el tamaño medio celular es de $0,225 \mu^{3}$ y las distribuciones son platicúrticas $(c=2,73)$ mientras que por debajo las células disminuyen de tamaño $\left(0,158 \mu \mathrm{m}^{3}\right.$ a $6 \mathrm{~m}$. y $0,113 \mu \mathrm{m}^{3}$ a $7 \mathrm{~m}$.) y las distribuciones son cada vez más leptocúrticas $(c=6,21$ a $7 \mathrm{~m}$.) indicando una progresiva disminución de la actividad de crecimiento con la profundidad.

\section{DISCUSION}

Los resultados presentados en este trabajo indican que las poblaciones bacterianas fotosintéticas que se desarrollan en Cisó y Cullera están activamente creciendo en la parte superior de la lámina y prácticamente no existe crecimiento ni fotosintesis en el punto de máxima acumulación de bacterias y por debajo de éste. Las elevadas concentraciones de Chromatium y de Chlorobium atenúan fuertemente la penetración de la luz de modo que la energía luminosa que reciben en profundidades donde se detecta la máxima concentración de células puede ser inferior a $1 \mu \mathrm{E} / \mathrm{m}^{2}$ seg, valor por debajo del cual no existe creciniento fotosintético en el laboratorio. 
Se observa por lo tanto una discordancia entre las profundidades donde se registra el máximo crecimiento y actividad, y la zona de acumulación de las células. Dicha acumulación tiene lugar en la quemoclina, situación permanente en lagos meromícticos y estuarios (CULVER \& BRUNSKILL, 1969; GORLENKO \& LEVEBA, 1971; INDREBO et al. 1977) o en la termoclina en los lagos holomícticos anaeróbicos durante la estratificación térmica estival (COHEN et al., 1977; GUERRERO etal., 1980).

Tanto en Cisó como en Cullera, la máxima acumulación de biomasa se detecta en el punto medio del gradiente, lo cual permite pensar en que las células son frenadas en su proceso de sedimentación por un incremento en la densidad del agua siguiendo dicho proceso la ley de Stokes. Los resultados de la cinética de la biomasa y contenido especifico de pigmentos fotosintéticos en la laguna de Cisó apoyan la hipótesis de que existe un proceso importante de sedimentación de las células durante la estratificación. En Cisó a profundidades en que no es posible un metabolismo fotosintético por falta de energía luminosa (por debajo de la lámina a $7 \mathrm{~m}$. de profundidad) se observa una tasa de aumento de la biomasa de Chromatium de 0,021/ días que es similar al observado en la parte superior de la lámina en donde el crecimiento es activo. Asimismo el contenido específico en bacterioclorofilas en las células decrece con la profundidad indicando una degradación de las estructuras fotosintéticas (MONTESINOS, 1982). Dicha degradación es también apreciable en cortes ultrafinos $\mathrm{de}^{-t}$ Chromatium examinados con el microscopio electrónico de transmisión (ESTEVE et al., 1980).

Sin embargo en las células de la capa superior (desde la superficie hasta la capa de máxima concentración de células) no se detectan cambios fisiológicos ni ultraestructurales. En este sentido es evidente que las células de Chromatium situadas por encima del punto medio del gradiente están sometidas a una iluminación homogénea que consiguen gracias a su movilidad mediante pro. cesos de fototaxis y quimiotaxis, proceso que viene favorecido por la presencia de un gradiente fisicoquímico que actúa como freno de la tendencia normal de sedimentación de las células en un ambiente sin turbulencia.

BIBLIOG RAFIA

BRADFORD, M.M. 1976. A rapid and sensitive method for the quantitation of microgram quantities of protein utilizing the principle of protein-dye binding. Anal. Biochem., 72: 248254.

COHEN, Y.; KRUMBLIN, W.E. \& SHILO, M. 1977 Solar Lake (Sina1). 3. Bacterial distribution and production. Limmol. Oceanogr ., 22: 621-634.

CULVER, D.A. \& BRUNSKILL, G.D. 1969. Fayetteville Green Lake. Studies of primary production and zooplankton in a meromictic marl lake. Limnol. Oceanogy : 14:862-873.

ISTEVE, I.; MONTESINOS, E.; ABELLA, C. \& GUERRERO, R. 1980. Changes in the ultraes tructure of the purple sulfur bacteria Chromatium minus depending on the variation of light in a natural habitat. Electron Microscopy, 2 : 456-457.

GOLTERM AN, H.L .; CLYMO, R.S. \& OHNSTAD, M.A.M. (eds.). 1978. Methods for physical and chemical analysis of fiesh waters. Blackwell Oxford, 2a ed.

GORLENKO, V.M \& LIVVIBBA, G.V 1971 . Vertical distribution of photosynthetic bacteria in the Kononier lake in the Mari, USSR. Microbiology, 40: 651-652.

GUERRl:RO, R. \& ABI:LLA, C. 1978. Dinámica espacio-temporal de las poblaciones bactcrianas fotosintéticas en una laguna anaerobia de aguas sulfurosas. Oecol. A quatica, 3: 193-205.

GLERRIERO, R.; MONTISSINOS, F.: ESTIVI: I. \& ABF:LLA, C. 1980. Physiological adaptation and growth of purple and grcen sulfur bacteria in a meromictic as compared to a holomictic lake. Developments in Hydrobiology', 3: 161 171.

HOBB II:, J.E; DALEY, R.J. \& JASPIER, S. 1977. Use of Nuclepore filter for counting bacteria by fluorescence microscopy. Appl. Environ. Microbiol.; $33: 1.225-1.228$. 
INDREBO, G.; PENGERUD, B. \& DUNDAS, I. 1979. Microbial activities in a permanently stratified stuary. I. Primary production and sulfate reduction. Mar. Biol.; 51: 295-304.

MONTESINOS, E. 1982. Ecofisiología de la fotosintesis bacteriana. Tesis Doctoral. Universidad Autónoma de Barcelona.

PARKIN, T.B. \& BROCK, T.D. 1980. Photosyn thetic bacterial production in lakes: The effects of light intensity. Limnol. Oceanogr., 25: 711 718.

TAKAHASHI, M. \& ICHIMURA, S. 1970. Photosynthetic properties and growth of photosynthetic sulfur bacteria in lakes. Limnol Ocea- nogr.; 15: 924-944.

TRÜPER, H.G. \& GENOVESE, S. 1968. Characterization of photosynthetic sulfur bacteria causing red water in lake Faro (Messina, Sicily). Linurol. Oceanogr., 13: 225-232.

VOLLENWEIDER, R.A. (ed.). 1974. A Manual on Methods for Measuring Primary Production in Aquatic Environinents. IBP Handbook No. 12. Blackwell Scientific Publications, Oxford.

ZARITSKY, A. \& PRITCHARD, R.H. 1973. Changes in cell size and shape associated with changes in the replication time of the chromosome of Escherichia coli. J. Bacteriol., 114: 824-837. 